\title{
APUNTES FRAGMENTARIOS SOBRE LOS ESTUDIOS LITERARIOS LATINOAMERICANOS 1970-1992
}

\author{
POR \\ Carlos Garcia-Bedoya M. \\ University of Pittsburgh
}

Los estudios literarios latinoamericanos son ya un campo lo suficientemente amplio e intrincado para que un balance de su actividad en los años más recientes sea una empresa aventurada, mas no por ello novedosa. ${ }^{1}$ Si la asumo es con la clara conciencia de intentar una aproximación fragmentaria y llena de vacíos. Podría justificarla con alguna fácil argucia "postmoderna", pero prefiero considerarla una aproximación preliminar a un tema que merece tratamiento exhaustivo. Queda entonces claro, y esta advertencia será válida para todo el trabajo, que no pretendo cubrir todas las facetas de asunto tan vasto, que los vacíos son innúmeros e inevitables dadas las limitaciones apuntadas, y que si cito o comento a tal o cual autor o libro, no lo hago en detrimento de otros, sino ante todo a manera de ilustración de algunos derroteros por los que transita nuestra disciplina. Al emplear este último vocablo dejo establecido que me ocupo de los estudios literarios en tanto saber sistemático y organizado, esto es en tanto disciplina científica - literaturwissenschaft-, (siempre que definamos ciencia en un sentido amplio, no por supuesto en el de las ciencias nomotéticas), integrada al vasto campo de las ciencias sociales. Una limitación final: se hace referencia aquí solamente a la producción de los estudiosos latinoamericanos, sin abordar la contribución de los latinoamericanistas extranjeros.

1. Hacia fines de los sesentay comienzos de los setentalos estudios literarios latinoamericanos reciben el impacto de sucesivas oleadas de novedades teóricas, procedentes sobre todo de Francia, desde los estructuralismos (recuperación đel viejo formalismo ruso incluida) y la semiótica, hasta las diversas sociocríticas, el postestructuralismo y las teorías de la

\footnotetext{
${ }^{1}$ He tomado especialmente en cuenta, sin por ello desconocer los méritos de otros anteriores, los trabajos de Saúl Sosnowski "Sobrela crítica de la literatura hispanoamericana: balance y perspectivas", Cuadernos Hispanoamericanos 443 (1987): 143-159 y de Jean Franco "Tendencias y prioridades de los estudios literarios latinoamericanos" Escritura 11 (1981) 7-20. La Revista de Crítica Literaria Latinoamericana dedicó un número monográfico $(31-32,1990)$, organizado por países, a la evaluación de quince años de crítica literaria latinoamericana y latinoamericanista. Me ha sido también de mucha utilidad el libro de Raúl Bueno, Escribir en Hispanoamérica. Ensayos sobre teoría y crítica literarias (Lima-Pittsburgh: Latinoamericana Editores, 1991), en el que se efectúa un balance de los logros de una vertiente central de los recientes estudios literarios latinoamericanos.
} 
recepción. Esta proliferación de enfoques se vivía en un ambiente de cierta euforia: América Latina estaba cambiando.

En efecto, así era. Un continente tradicionalmente agrario vivía una vertiginosa urbanización. Se experimentaban nuevas modalidades de industrialización. Cundían las expectativas desarrollistas: la modernización estaba en marcha. Desde otras perspectivas ideológicas, también habían razones para el optimismo: la revolución cubana había abierto las puertas de la transformación social y la victoria de Allende confirmaba la tendencia histórica. Simultáneamente, la literatura latinoamericana vivía un florecimiento inusitado y alcanzaba un vasto reconocimiento internacional, tanto de crítica como de mercado. América Latina era el continente de la esperanza.

A comienzos de la década del noventa, parece más bien el continente del desencanto. Después de las terribles experiencias dictatoriales, sobre todo en el cono sur, y de la no menos devastadora y más generalizada de la crisis económica, América Latina ha cambiado sin duda, pero parecieran canceladas las expectativas tanto de la acelerada modernización desarrollista como de la revolución social. Se perdió el protagonismo en algún momento alcanzado y del "boom" literario no subsisten sino la fama y la fortuna de unos pocos elegidos. Y en los estudios literarios, se pasó de la euforia antropofágica a la proliferación babélica. Vayamos al examen de ese proceso.

2. Como toda la cultura latinoamericana (cultura marcada por la experiencia colonial), los estudios literarios experimentan las pulsiones rivales de autonomización e internacionalización. De un lado, esfuerzo por constituir su propio objeto de estudio, por delimitar un corpus (sobre todo nacional, a escala hispano o latinoamericana el esfuerzo será más tardío). Del otro, esfuerzo por incorporar un instrumental teórico moderno, generado en los países centrales. Los diversos corpus nacionales se articularon bajo las premisas del positivismo y con miras a consolidar las identidades particulares. A esta etapa de organización de las historias literarias nacionales, a veces prolongada desmesuradamente, le suceden esfuerzos por cambiar los parámetros del trabajo crítico e histórico. Tenemos así los aportes bastante personales de Pedro Henríquez Ureña, Alfonso Reyes o José Carlos Mariátegui, y también la irrupción, más generalizada, de la estilística, con particular fuerza en Buenos Aires en torno a Amado Alonso. En las décadas del 50 y 60 convergirán los aportes de otras corrientes, como ciertas facetas del New Criticism (sobre todo en el Brasil), cuyo impacto es visible por ejemplo en la obra de Afranio Coutinho; o la crítica fenomenológica, representada en la obra de Félix Martínez Bonati o Alberto Escobar. A fines de los 60 y comienzos del 70 la dinámica innovadora se acelera hasta alcanzar los confines del vértigo. Pero el dinamismo es general en el ambiente intelectual latinoamericano. En especial se vigorizan las nuevas disciplinas de las ciencias humanas y sociales, con un impacto indudable sobre los estudios literarios.

Para tener una imagen del estado de la disciplina al comenzar nuestro periodo de estudio, nada mejor que echar una mirada al volumen América Latina en su literatura, publicado bajo la dirección de César Fernández Moreno y con el auspicio de la Unesco. ${ }^{2}$ En

2 César Fernández Moreno (compilador), América Latina en su literatura ( México: Siglo XXI, 1972). 
él se recogen desde los aportes de algunos sobrevivientes de la crítica más tradicional, hasta los de aquellos que comienzan a introducir las últimas novedades metropolitanas. Ya entonces la literatura latinoamericana había alcanzado una consagración internacional que implicaba un reto para sus estudiosos: de algún modo el "boom" creativo exigía un "boom" reflexivo. Se podría entonces intentar una crónica de los distintos avatares de los estudios literarios desde ese momento hasta el presente, pero ello exigiría una exhaustividad que es por ahora imposible, y probablemente sería además un esfuerzo vano, porque si algo caracteriza a nuestra disciplina en América Latina es la borrosidad de las fronteras entre las diversas opciones.

Pocos son los adherentes ortodoxos a una específica corriente teórica. La norma es más bien un cierto eclecticismo, el recurso a instrumentos conceptuales de distinta procedencia en función de problemas específicos, la práctica del bricolage a la que gustaba aludir Ángel Rama. Tampoco la debilidad de las instituciones académicas resulta favorable para la constitución de escuelas de pensamiento. Como lo apreciaremos más adelante, en la obra de un mismo autor es posible ver en acción herramientas teóricas divergentes y hasta a veces difícilmente conciliables.

Conviene sin embargo apuntar algunas opciones centrales en torno a las cuales se tensan fuerzas en la disciplina. Una primera disyuntiva gravitante es la opción entre enfoques textualistas o inmanentistas y enfoques que de diversos modos trascienden el espacio textual hacia la dimensión más vasta de lo social. Pero las privilegiadas suelen ser las opciones intermedias en sus todas sus posibles variantes: pocos cultivan el inmanentismo puro o el sociologismo estrecho. Una segunda disyuntiva, que dio lugar a un amplio debate (abordado más adelante), oponía la tentación cosmopolita a la tentación autoctonista: incorporar con maestría el arsenal teórico occidental o producir esforzadamente un instrumental propio. Se ponía así en juego la dialéctica de lo particular y lo universal, enfrentada con mayor o menor acierto por los diversos estudiosos, cada cual labrando su rumbo entre Escila (alienación) y Caribdis (provincianismo).

Pero de mayor interés que configurar estas tensiones generales resultará verlas plasmadas en el trabajo de algunos especialistas representativos. Exploraremos pues por medio de ejemplos concretos los caminos recorridos por la crítica, la teoría y la historia literaria latinoamericanas.

3. Me parece justo comenzar por alguien que ha hecho destacadas contribuciones en esas tres vertientes de los estudios literarios, aún si tal vez sus obras más significativas son anteriores a nuestro periodo: me refiero a António Candido, seguramente la mayor figura viva de nuestra disciplina. Candido ha cultivado la crítica en multitud de artículos y en monografías consagradas a Graciliano Ramos o Silvio Romero, la historia literaria en su ya clásico Formação da Literatura Brasileira, y la teoría en sus consistentes reflexiones sobre las relaciones entre literatura y sociedad. ${ }^{3}$ El influyente ensayo "Literatura y subdesarrollo"

\footnotetext{
${ }^{3}$ Introdução ao Método Crítico de Sillvio Romero (São Paulo, 1945). Ficção e Confissão; Estudo sobre a Obra de Graciliano Ramos (Rio de Janeiro: José Olympio,1956). Formação da Literatura Brasileira; Momentos Decisivos (São Paulo: Martins, 1959). Literatura e Sociedade; Estudos de Teoria e História Literária (São Paulo: Nacional, 1965). Algunos de sus trabajos más recientes están reunidos en A Educação Pela Noite e Outros Ensaios (São Paulo: Editora Atica, 1987).
} 
(recogido en la ya mencionada compilación América Latina en su literatura), puede considerarse representativo de su enfoque sociológico que nunca pierde de vista la especificidad de lo literario. Detecta la emergencia entonces reciente de la conciencia de subdesarrollo, y las consecuencias de tal fenómeno socioeconómico a nivel de vulnerabilidad cultural ante lo extranjero, en sus dos vertientes de alienación y provincianismo. Destaca las modalidades de apropiación creativa de los aportes metropolitanos y, a contracorriente de una opinión entonces muy vigorosa, apunta la significación fecundante del regionalismo y su reformulación por escritores como Guimarães Rosa, Rulfo o García Márquez.

En una dirección muy diversa se desenvuelve la figura de Ana María Barrenechea. Integrante destacada del compacto grupo de estilistas de Buenos Aires, Barrenechea tenía ya también una sólida obra en su haber ${ }^{4}$ pero no era de los que se fosilizan en determinados parámetros teóricos, sino de los tienen la solvencia necesaria para asimilar críticamente las novedades. Enriqueció su ya sólida formación lingüística, filológica y estilística con los aportes del estructuralismo, la crítica genética o la teoría de los speech acts. Sobre la base de las reflexiones de Tzvetan Todorov, ha abordado el género fantástico, discutiendo los contextos socioculturales que operan como marcos de referencia del género. ${ }^{5}$ Ha trabajado asiduamente sobre la narrativa rioplatense (Borges, Felisberto Hernández, Cortázar). Sobre el último, había consagrado ya un artículo a "La estructura de Rayuela de Julio Cortázar" (incluido en el citado Textos hispanoamericanos) y en 1983 editó el Cuaderno de bitácora de Rayuela ${ }^{6}$ en el que incluyó un largo estudio preliminar donde desarrolla uno de los escasos ejemplos de crítica genética rigurosa en Latinoamérica, examinando un conjunto de documentos pre-textuales proporcionados por Cortázar, cuyo análisis le permite enriquecer la comprensión de diversos niveles del texto definitivo.

La obra poética de Octavio Paz cuenta con el reconocimiento de un premio Nobel, pero su obra crítica no es poco significativa. La importancia de su crítica periodísticay de su labor como promotor de importantes revistas (primero Plural, luego Vuelta) es evidente. Pero, aunque no es un hombre plenamente integrado a la esfera académica, nos interesarán algunos de sus estudios. Mencionemos entre los más antiguos a sus reflexiones poetológicas de El arco y la lira o los ensayos de Cuadrivio (sobre Pessoa, Cernuda, Darío y López Velarde). ${ }^{7}$ Pero destacaré sobre todo dos estudios de nuestro periodo. En el primero, Los hijos del limo, intenta un ambicioso balance de la poesía occidental moderna desde el Romanticismo hasta la Posmodernidad, en el que sitúa a la poesía hispanoamericana, destacando la significación de sus momentos clave: el Modernismo y la Vanguardia. El

\footnotetext{
${ }^{4}$ Destaquemos sobre todo su estudio La expresión de la irrealidad en la obra de Jorge Luis Borges (México: El Colegio de México, 1957).

5 "Ensayo de una tipología de la literatura fantástica", y "La literatura fantástica: función de los códigos socioculturales en la constitución de un género" recogidos respectivamente en sus libros Textos hispanoamericanos. De Sarmiento a Sarduy (Caracas: Monte Avila, 1978) y El espacio critico en el discurso literario (Buenos Aires: Kapelusz, 1985) en los que se recopilan algunos de sus trabajos más importantes del período.

${ }^{6}$ Cuaderno de bitácora de Rayuela (Buenos Aires: Sudamericana, 1983).

${ }^{7}$ El arco y la lira (México: Fondo de Cultura Económica, 1956). Cuadrivio (México: Joaquín Mortiz, 1964).
} 
segundo es una voluminosa monografía sobre sor Juana: Sor Juana Inés de la Cruz o las trampas de la fe. ${ }^{8}$ En él intenta combinar historia, biografía y crítica literaria: situar a sor Juana y su obra en el contexto de la Nueva España barroca, explorar los enigmas biográficos de la escritora, en especial el de su discutida conversión final, y a través de tales mediaciones evaluar la obra. Si el esquema puede parecer algo tradicional, el resultado es estimulante y, como siempre en Paz, polémico.

Emir Rodríguez Monegal fue uno de los más activos dinamizadores de la vida cultural en América Latina, sobre todo a través de su actividad periodística, por ejemplo en las páginas de Marcha o de Mundo Nuevo. Su crítica siempre informada y consagrada a la modernización de la literatura latinoamericana hizo de él uno de los críticos oficiales y de los promotores más entusiastas del "boom" narrativo. Personaje controversial, sobre todo a nivel de sus alineamientos políticos, ha ejercido una indudable influencia, ya por su labor académica en Estados Unidos, ya por la solvencia de sus análisis, en general poco inclinados a la reflexión teórica, pero de gran sensibilidad estética y vasta información. Tenía ya en su haber una monografía consagrada a Pablo Neruda, ${ }^{9}$ pero interesa comentar su Jorge Luis Borges. A Literary Biography. ${ }^{10}$ Biografia literaria (curiosamente el biógrafo precedió al biografiado en el tránsito final), es decir, conforme a la vieja fórmula, examen de vida y obra. Pero en una vida tan "prosaica" como la de Borges los acontecimientos mayores son los acontecimientos intelectuales: biografía más de la obra que del autor, seguimiento de las confluencias culturales que marcaron la carrera de alguien destinado desde siempre a la escritura. Si el esquema tradicional resulta operativo, es por la fluidez de la narrativa, por la lucidez en el establecimiento de conexiones que iluminan la producción textual de uno de los maestros indudables de las letras latinoamericanas.

Otra de las figuras capitales de las letras latinoamericanas es abordada por Roberto González Echevarria: me refiero a Alejo Carpentier. " Discípulo de Rodríguez Monegal en Yale, tomó allí también contacto con el grupo deconstructivista nucleado en torno a Paul de Man. Las reflexiones de éste y de Derrida ${ }^{12}$ han dejado huella en su Alejo Carpentier. The Pilgrim at Home, pero González Echevarría practica una versión moderada de la deconstrucción, combinada con instrumentos más tradicionales provenientes de la historia de las ideas o de la filología, que le permiten examinar el impacto en la trayectoria del narrador cubano de pensadores tales como Spengler, Fernando Ortiz, Ortega y Gasset o Sartre. Interesado en detectar las discontinuidades en la obra carpenteriana, establece las

${ }^{8}$ Los hijos del limo (Barcelona: Seix Barral, 1974). Sor Juana Inés de la Cruz o las trampas de la fe (México: Fondo de Cultura Económica, 1982).

${ }^{9}$ El viajero inmóvil: Introducción a Pablo Neruda (Buenos Aires: Losada, 1966).

${ }^{10}$ Jorge Luis Borges. A Literary Biography (Nueva York: E. P. Dutton, 1978). Escrito originalmente en inglés, la primera edición en español es de 1987.

${ }^{11}$ Alejo Carpentier. The Pilgrim at Home (Ithaca: Cornell University Press, 1977) (Segunda edicion: Austin, University of Texas Press, 1990). Mencionemos también sus libros Isla a su vuelo fugitiva (Madrid: Porrúa Turanzas, 1983) y The Voice of the Masters: Writing and Authority in Modern Latin American Literature (Austin: University of Texas Press, 1986).

${ }^{12}$ En su más reciente libro Myth and Archive: A Theory of Latin American Narrative (Cambridge; New York: Cambridge University Press, 1990), se acerca más a los enfoques de Foucault. 
etapas mayores en ella y ve un momento central de ruptura en la producción de Los pasos perdidos, lo que le permite desmantelar la imagen de un Carpentier encasillado en el "realismo mágico" o "lo real maravilloso", característico solamente de su segunda etapa (El reino de este mundo), mientras que una primera se vincularía con el afro-cubanismo (EcueYamba-O), la tercera, más sartreana, cuestiona la situación del escritor latinoamericano (Los pasos perdidos), y en la cuarta predominaría una escritura barroca ( $E l$ siglo de las luces).

Desde una óptica de inspiración marxista, Roberto Schwarz ha consagrado sostenida atención a la obra de Machado de Assis. ${ }^{13}$ Trabajando en los derroteros marcados por Antonio Candido, incorpora en su trabajo crítico las reflexiones de pensadores tales como Lukács, Goldmann, Benjamin, Adorno o Sartre. En el volumen inicial de su díptico sobre Machado de Assis, Ao Vencedor as Batatas, dedica un primer capítulo "As idéias fora de lugar" a examinar el desfase en el Brasil entre instituciones liberales y realidad esclavista. Examina luego la introducción de la novela en el Brasil, en especial por intermedio de Alencar, para abordar finalmente el estudio de las novelas tempranas de Machado, a las que considera organizadas en torno a una racionalización del paternalismo. En el segundo volumen, Um Mestre na Periferia do Capitalismo-Machado de Assis-, analiza en detalle la novela que marca la plena madurez del narrador brasileño, Memórias Póstumas de Brás Cubas, diseñando las conexiones entre sus estructuras formales y sus contenidos ideológicos (por ejemplo la intromisión irreverente del narrador como expresión de una desfachatez de clase), de manera tal que le permite subvertir la imagen tradicional de un Machado de Assis desvinculado de la realidad brasileña y encapsulado en el cosmopolitismo.

Antonio Cornejo Polar consagró una monografía al conjunto de la obra de José María Arguedas, ${ }^{14}$ en la que su inicial formación filológica se enriquecía con los aportes de la fenomenología y la sociología literaria de Goldmann. Sucesivos estudios hicieron de él el más importante especialista en la narrativa indigenista andina. ${ }^{15}$ A Cornejo le interesa no tanto brindar una visión diacrónica del indigenismo, sino desentrañar la organización estructural de la novela indigenista, en base al desarrollo de la distinción introducida por José Carlos Mariátegui entre literatura indígena y literatura indigenista. Cornejo detecta los rasgos contradictorios de una narrativa en la que el referente, de un lado, y las instancias de producción, recepción y textual, del otro, se vinculan a distintos universos socioculturales. Para dar cuenta de tal fenómeno, Cornejo introduce la categoría teórica de heterogeneidad. El examen de la heterogeneidad literaria en un espacio social desgarrado lo condujo a la reflexión sobre la pluralidad de sistemas literarios que coexisten en sociedades tales como la peruana: un sistema literario ilustrado escrito en español, otro popular también en

${ }^{13}$ Ao Vencedor as Batatas (São Paulo: Duas Cidades, 1977). Um Mestre na Periferia do Capitalismo -Machado de Assis- (São Paulo: Duas Cidades, 1990). Citemos también entre sus recopilaciones de ensayos A Sereia e o Desconfiado (Rio de Janeiro: Paz e Terra, 1981) (segunda edición) y Que Horas São? (São Paulo: Companhia das Letras, 1987).

${ }^{14}$ Los universos narrativos de José Maria Arguedas (Buenos Aires: Losada, 1973).

${ }^{15}$ Diversos estudios recogidos en Sobre literatura y crítica literaria latinoamericanas (Caracas: Ediciones de la Facultad de Humanidades y Educación de la Universidad Central de Venezuela, 1982) y en La novela peruana (Lima: Horizonte, 1989). En Literatura y sociedad en el Perú: la novela indigenista (Lima: Lasontay, 1980), presenta un balance general de esa corriente. 
español, y finalmente las literaturas en lenguas nativas. Para dar cuenta de tal diversidad, define a la literatura peruana como totalidad contradictoria, ${ }^{16}$ y luego ha propuesto, de manera muy sugerente, la extensión de tal categoría para dar cuenta del conjunto de la literatura latinoamericana.

La vasta obra de Ángel Rama, truncada por un infortunado accidente en su momento de mayor productividad, es sin duda la más importante del período que estamos examinando. $\mathrm{Su}$ actividad incansable se prodigó en el periodismo (destacadamente en Marcha, pero también en toda la prensa latinoamericana), en prólogos y antologías, en el vasto proyecto editorial de Biblioteca Ayacucho, en el impulso a una revista como Escritura, en sus clases (en Uruguay, en Puerto Rico, en Venezuela, en Estados Unidos) y por cierto en sus libros. La crítica de Ángel Rama puede definirse como culturalista, en un sentido muy concreto: para él la cultura era una instancia mediadora clave entre la esfera de la literatura y la esfera de lo social. Sobre la base de esta orientación solía poner en juego conceptualizaciones de la más diversa procedencia (de Lévi-Strauss a Fernando Ortiz, de Tinianov a Pedro Henriquez Ureña, de Walter Benjamin a José Carlos Mariátegui), en función de los requerimientos específicos del análisis, con una apertura cosmopolita, pero siempre atento a la herencia de la tradición cultural latinoamericana. De los muchos temas que inquietaron la creatividad de Rama dos de los más recurrentes son el Modernismo y el proceso de la narrativa latinoamericana del siglo XX. Al primero, además de numerosos artículos, dedicó dos importantes libros, ${ }^{17}$ en los que estudia la relación entre procesos de modernización socioeconómica y un momento al que considera crucial para el devenir futuro de las letras latinoamericanas. Al segundo consagró importantes artículos panorámicos - "Medio siglo de narrativa latinoamericana (1922-1972)", "El Boom en perspectiva" , "La tecnificación narrativa", ${ }^{18}$ entre otros-y su libro Transculturación narrativa en América Latina. ${ }^{19}$ En ellos ubicaba al llamado Boom ya no como un momento adánico, sino en el proceso de la tradición narrrativa latinoamericana, mostrando las relaciones de tantas de sus obras representativas con el regionalismo de los años 20 ó 30 . La narrativa de la transculturación es justamente para él aquélla que es capaz de recoger la herencia cultural popular de sus respectivas regiones y ponerlas en relación con los más audaces y modernos recursos narrativos (tal como lo hacen García Márquez, Rulfo, Arguedas, Roa Bastos o Guimarães Rosa). Tal vez su obra más influyente sea la póstuma La ciudad letrada ${ }^{20}$ en la que, superando los marcos restringidos de los estudios literarios, examina el papel de la intelectualidad en la trayectoria sociocultural de América Latina. Examina especialmente los avatares de las relaciones entre grupos letrados y poder, desde la ciudad ordenada

\footnotetext{
16 "La literatura peruana: totalidad contradictoria", Revista de Crítica Literaria Latinoamericana 18 (1983). También incluido en el libro La formación de la tradición literaria en el Perú (Lima: CEP, 1989).

${ }^{17}$ Ruben Dario y el Modernismo (Caracas: Ediciones de la Biblioteca de la Universidad Central de Venezuela, 1970). Las máscaras democráticas del Modernismo (Montevideo: Fundación Ángel Rama, 1985).

${ }^{18}$ Incluidos en su La novela en América Latina: Panoramas 1920-1980 (Bogotá: Procultura, 1982).

19 Transculturación narrativa en América Latina (México: Siglo XXI, 1982).

${ }^{20}$ La ciudad letrada (Hanover, NH: Ediciones del Norte, 1984).
} 
articulada por los conquistadores, hasta la ciudad revolucionada impactada por los movimientos de masa del siglo XX.

El desplazamiento hacia los estudios culturales es bastante visible en el trabajo de Beatriz Sarlo. Se había iniciado en el ámbito de la sociología de la literatura ${ }^{21}$ y le preocupaban las barreras entre los especialistas de la producción intelectual y las más vastas esferas sociales, preocupación que intentó enfrentar desde la dirección de una revista tan importante como Punto de vista (cuyo rol bajo la dictadura militar argentina es inútil recalcar). Insatisfecha con las limitaciones de la crítica literaria académica, orientó sus esfuerzos hacia campos que escapaban a los parámetros más tradicionales de la disciplina. Así, en El imperio de los sentimientos ${ }^{22}$ analiza la literatura sentimental para consumo de masas difundida por revistas argentinas estrictamente contemporáneas de la vanguardia, y examina esta producción (generalmente confinada al infierno de la subliteratura) con las herramientas del análisis textual semiótico y de la teoría de la recepción, para situarlas en tanto expresión de la vida cotidiana. Pero su libro más importante es sin duda Una modernidad periférica: Buenos Aires 1920 y $1930 .{ }^{23}$ Investigación que se mueve en el heterogéneo campo cultural de una moderna metrópolis periférica, desplazándose de los productores culturales al público, de la literatura a las instituciones, en una multiplicidad de lecturas que dialogan con Barthes, Benjamin, Raymond Williams, Pierre Bourdieu o Marshall Berman, entre tantos otros, examinando desde el discurso del erotismo femenino hasta la relación entre política y literatura en tiempos de la Vanguardia.

4. Si en la crítica literaria la producción latinoamericana ha sido abundante y diversa, no lo ha sido tanto en los campos de la teoría y la historia literarias. En la teoría han predominado los trabajos de divulgación de las más recientes conceptualizaciones europeas o norteamericanas, aunque es indispensable destacar la importante reflexión en torno a las posibilidades de desarrollos teóricos más autónomos.

Fue tal vez Roberto Fernández Retamar quien más contribuyó a desencadenar el debate, al reclamar la urgencia de una teoría de la literatura latinoamericana, ${ }^{24}$ asunto que concitó la atención principalmente de aquellos que optaban por una perspectiva sociocultural en los estudios literarios. Más que hacer una crónica de peripecias intelectuales, vale la pena presentar un balance de ese debate, tal como lo formuló Raúl Bueno. ${ }^{25}$ Rechazada la tentación autárquico-provinciana, una teoría de la literatura latinoamericana, inscrita en la teoría general de la literatura, sólo puede consistir en un cuerpo de reflexiones que permita

${ }^{21}$ Véanse sus libros en colaboración con Carlos Altamirano: Conceptos de sociología literaria (Buenos Aires: CEAL, 1980) y Literatura y Sociedad (Buenos Aires: Hachette, 1983).

${ }^{22}$ El imperio de los sentimientos (Buenos Aires: Catálogos Editora, 1985).

${ }^{23}$ Una modernidad periférica: Buenos Aires 1920 y 1930 (Buenos Aires: Ediciones Nueva Visión, 1988).

${ }^{24}$ Véanse especialmente sus textos "Algunos problemas teóricos de la literatura hispanoamericana" y "Para una teoría de la literatura hispanoamericana", recopilados en su Para una teoría de la literatura hispanoamericana y otras aproximaciones (La Habana: Casa de las Américas, 1975).

${ }^{25}$ Escribir en Hispanoamérica. Ensayos sobre teoría y crítica literarias (Lima/Pittsburgh: Latinoamericana Editores, 1991). 
dar cuenta de las especificidades del campo literario latinoamericano. Los avances de tal proyecto han sido relativamente limitados y consisten, de un lado, en ciertas precisiones epistemológicas, y del otro, en algunos dipositivos teóricos específicos forjados en el curso del trabajo crítico sobre un fenómeno literario determinado. A este nivel, ya se ha hecho mención al concepto de transculturación, afinado por Ángel $\mathrm{Rama}^{26}$ para los estudios literarios, o a las categorías de heterogeneidad y totalidad contradictoria introducidas por Antonio Cornejo Polar, sin olvidar las reflexiones de António Candido sobre la dialéctica literatura/sociedad. Tal vez la consecuencia más importante del debate sea la aceptación general de la ampliación del campo de la literatura latinoamericana, para abarcar, además de la literatura ilustrada, a las literaturas populares (incluyendo las de lengua indígena) y alternativas.

Pero algunos estudiosos han consagrado sus mayores desvelos a la teoría, y quiero destacar por lo menos a dos. Uno de ellos es Walter Mignolo. A Mignolo le interesa construir una teoría del texto literario, en función de un paradigma de rigurosa cientificidad, que exige específicos niveles de formalización. Para esta tarea, recurre a una variedad de enfoques lingüísticos (estructuralismo, generativismo, pragmática), al arsenal del formalismo ruso, el estructuralismo francés y las diversas semióticas, muy en especial la de Lotman y la escuela de Tartu. En su primer libro, Elementos para una teoria del texto literario, ${ }^{27}$ asume la definición lotmaniana de la literatura en tanto sistema modelizador secundario: el texto literario es una estructura verbo-simbólica regida por una metalengua (luego preferirá el término metatexto) que lo especifica como tal: el objeto central de la teoría literaria es para él el paso del sistema modelizador primario (el de la lengua natural) al secundario, al que denomina proceso de semiotización. Desde esta perspectiva, analiza la configuración del sistema primario, del secundario y del comunicacional. En Teoria del texto $e$ interpretación de textos ${ }^{28}$ introduce algunas reformulaciones y desarrollos complementarios. Enfatiza la diferencia entre comprensión teórica (constitutiva de un saber científico) y comprensión hermeneútica (para él constitutiva únicamente de la experiencia literaria), y rechaza por tanto la posibilidad de un saber intersubjetivo sustentado en la sistematización de la reflexión sobre la experiencia literaria (lo que se suele denominar crítica o interpretación de textos). De allí que en sus enfoques de textos concretos ${ }^{29}$ (le disgustaría que los califiquemos de crítica literaria o de hermenéutica textual), se interese en examinar la operatividad de determinadas categorías teóricas en un marco textual determinado, y no las particularidades específicas de éste. Son importantes sus estudios sobre textos coloniales, especialmente las crónicas, a los que aborda a partir de la categoría de discurso, que le permite superar los estrechos límites del canon colonial tradicional. ${ }^{30}$

${ }^{26}$ Otros aportes específicamente teóricos de Rama en sus estudios "Sistema literario y sistema social en Hispanoamérica"en el volumen colectivo Literatura y praxis en América Latina (Caracas: Monte Avila, 1974) y "Literatura y clase social", Escritura 1 (1976).

${ }^{27}$ Elementos para una teoria del texto literario (Barcelona: Editorial Crítica, 1978).

${ }^{28}$ Teoría del texto e interpretación de textos (México: Universidad Autónoma de México, 1986).

${ }^{29}$ Muchos de ellos recopilados en Textos, modelos y metáforas (Veracruz: Universidad Veracruzana, 1984).

${ }^{30}$ Véase, entre otros muchos, su artículo "La lengua, la letra, el territorio (o la crisis de los estudios literarios coloniales)", Dispositio 28-29 (1986). 
El otro teórico al que quisiera hacer referencia es Luiz Costa Lima. Más que a construir un sistema teórico global, Costa Lima aspira a explorar algunos conceptos clave, a los que arranca del ámbito puramente literario. El de mímesis, por ejemplo, al que atribuye un alcance mucho mayor que el simplemente estético: es una de las formas del discurso del inconsciente, que sólo adquiere carácter estético cuando el receptor lo decodifica a partir de su situación histórica. En el texto literario, es lo ficcional lo que permite descubrir en la alteridad del texto semejanzas con los valores de quien lo recibe. Desde esta perspectiva puede comprobar cómo la mímesis es una categoría operante en la poesía moderna, de Baudelaire aEliot. ${ }^{31}$ Pero tampoco ficcional es para nuestro autor una categoría estrictamente literaria, puesto que puede existir una ficción cotidiana: el carácter literario de un texto se define a partir de marcos discursivos históricamente configurados por un determinado período o cultura. Constata entonces que gran parte de la literatura occidental se caracteriza por un veto a lo ficcional, que para justificarse en el arte tiene que ponerse al servicio de la razón. La razón clásica relegó la ficción a una posición subalterna: le cupo al romanticismo levantar ese veto impuesto a la ficción. La exploración de los mecanismos de control del imaginario lleva a nuestro autor por los más variados espacios literarios, desde el medioevo europeo hasta la literatura latinoamericana contemporánea. ${ }^{32}$ También examina el concepto de narrativa, entendida como establecimiento de una organización temporal, tanto en el campo de la ficción como en el de la historia (e incluso el de la ciencia) y le señala dos límites a su acción: de un lado, el de la ley, en el sentido científico de la palabra, es decir una formulación cuya adecuación no depende de contextos particulares, del otro el del poema lírico, palabra del instante, donde el tiempo se inmediatiza como presencia. Esta expansión del concepto de narrativa (o también del de metáfora) implica una crítica del paradigma científico modelado exclusivamente en torno a las ciencias naturales y un develamiento de las continuidades entre éstas y las ciencias sociales y humanas, favoreciendo un paradigma científico más atento a lo particular, más conciente de las limitaciones de la ciencia y menos vulnerable a los apremios de la razón instrumental. ${ }^{33}$

La historia literaria ha cosechado escasos frutos en este periodo. Dominada por el positivismo hasta tiempos muy recientes, esta imagen de disciplina arcaica confluyó con la desconfianza del estructuralismo y del postestructuralismo hacia el pensamiento histórico. En una reacción contra el biografismo y la obsesión por el dato, se pasó a privilegiar el análisis inmanentista de textos, mientras la historia literaria quedaba un tanto desacreditada, restringida más bien a un género divulgativo visto con desconfianza en los círculos académicos. Sin embargo, desde nuevas vertientes se viene produciendo una recuperación del trabajo histórico. ${ }^{34}$ No es posible detenerse a examinar lo sucedido en la esfera de las

\footnotetext{
${ }^{31}$ Mímesis e Modernidade. Formas das Sombras (Rio de Janeiro: Ediçoes Graal, 1980).

${ }^{32}$ O Controle do Imaginário. Razão e Imaginação no Occidente (São Paulo: Editora Brasiliense, 1984). Sociedade e Discurso Ficcional (Rio de Janeiro: Editora Guanabara, 1986).

${ }^{33}$ A Aguarrás do Tempo (Rio de Janeiro: Rocco, 1989).

${ }^{34}$ Son muy útiles para el procesamiento de tal recuperación las investigaciones de Beatriz González sobre la tradición historiográfica latinoamericana: Contribución al estudio de la historiografia literaria hispanoamericana (Caracas: Biblioteca de la Academia Nacional de Historia, 1985) y La historiografia literaria del liberalismo hispanoamericano del siglo XIX (La Habana: Casa de Las Américas, 1987).
} 
distintas literaturas nacionales. Bastará considerar dos proyectos que abordaron al conjunto de la literatura latinoamericana. Uno de ellos parece haber quedado trunco, debido a la muerte de su principal impulsor, Alejandro Losada. Con un conjunto de estudiosos europeos agrupados en AELSAL, se proponía elaborar una historia social de las literaturas latinoamericanas. Para ello había desarrollado una serie de reflexiones preliminares y existen una serie de colaboraciones parciales de los distintos participantes, ${ }^{35}$ pero después de su prematura desaparición parece haber quedado paralizado el proyecto. El otro es el impulsado por António Candido, Jacques Leenhardty Ángel Rama, y coordinado por Ana Pizarro, preparado en sendas reuniones en Caracas (1982) y Campinas (1983), con la participación de especialistas tales como António Candido, Antonio Cornejo Polar, Ángel Rama, Beatriz Sarlo o Roberto Schwarz, entre otros, ${ }^{36} \mathrm{y}$ que, después de muchas dilaciones, parece estar próximo a culminar. Es de esperar que en un futuro próximo, la historia literaria latinoamericana experimente una significativa dinamización. Algunos estudios específicos así parecen anunciarlo. ${ }^{37}$

5. A lo largo del período examinado, los estudios literarios latinoamericanos han sufrido importantes transformaciones: se ha procesado de manera confusay desigual la asimilación de un amplio abanico de enfoques teóricos y metodológicos, al mismo tiempo que se ha consolidado una tradición latinoamericana en la disciplina, con mayor éxito en la crítica que en la teoría o la historia literarias. Con todo, el panorama actual se caracteriza más por la confusión y la dispersión de los esfuerzos, al tiempo que se multiplican los retos. El de incorporar los estudios literarios en un horizonte de trabajo más vasto, el de los estudios culturales, sin perder su propia identidad, peligro tan real como el aislacionismo de la disciplina, y al que frecuentemente arrastra el entusiasmo. El de la ampliación del campo de estudio, en una doble faceta. De un lado, la necesidad de asumir una perspectiva latinoamericana, más allá de los linderos nacionales: en esto se han logrado importantes avances en el currículum de buena parte de las universidades de la región. De otro lado, el reto que plantea el nuevo espesor del corpus literario latinoamericano. Los productos culturales de los grupos sociales marginados o subalternos (entre ellos las mujeres) suponen un desafío inédito. Las literaturas populares y muy especialmente aquellas en lenguas

\footnotetext{
${ }^{35}$ Véase de Alejandro Losada La literatura en la sociedad de América Latina: Perú y el Río de la Plata, 1837-1880 (Frankfurt: K. D. Vervuert, 1983) y La literatura en la sociedad de América Latina (München: W. Fink, 1987). También la sección monográfica "Literatura y sociedad en América Latina: aportes del grupo de Berlín" de la Revista de Crítica Literaria Latinoamericana 30 (Lima/ Pittsburgh, 1989) y el Homenaje a Alejandro Losada (Lima: Latinoamericana Editores, 1987).

${ }^{36}$ Ana Pizarro (Coordinadora) Hacia una historia de la literatura latinoamericana (México: El Colegio de México-Universidad Simón Bolívar, 1987) y La literatura latinoamericana como proceso (Buenos Aires: Centro Editor de América Latina, 1985).

${ }^{37}$ Por lo menos mencionaré también el vasto esfuerzo de Çedomil Goiç en los tres tomos de Historia crítica de la literatura hispanoamericana (Madrid: Crítica, 1988), por él organizados siguiendo la pauta utilizada por Francisco Rico para el caso de la literatura española, útiles aunque estructurados centralmente sobre el esquema de la teoría de las generaciones. Si bien no es historia, menciono por su importancia al proyecto del Diccionario Enciclopédico de las Letras de América Latina, dirigido por Nelson Osorio y de próxima aparición.
} 
indígenas reclaman no sólo una mayor atención, sino aproximaciones más creativas, capaces de aprehender sus especificidades. Lo mismo sucede con los productos de la literatura de masas, erróneamente rotulados como subliteratura. En la propia literatura ilustrada son enormes los vacíos: se suele privilegiar exorbitantemente a algunas figuras consagradas, y áreas enteras quedan en la oscuridad. En algunas se vienen reparando deficiencias, como en la literatura colonial, pero sigue siendo ingente la tarea y reclama con urgencia aunar esfuerzos colectivos.

En sociedades donde los espacios institucionales de la cultura se caracterizan por la precariedad, los problemas se multiplican. En la mayoría de nuestros países la actividad editorial es raquítica, las tribunas escasas en periódicos y revistas y nulas en otros medios de comunicación, lo cual dificulta la necesaria comunicación con un público más vasto. Las instituciones académicas se caracterizan por la penuria económica y la escasez de recursos, a lo que se agrega el fenómeno generalizado de la inmigración de muchos de los mejores profesores, principalmente a Estados Unidos, ya por razones económicas o políticas. De allí que el rol de la academia norteamericana sea gravitante para el destino de la crítica latinoamericana. Si de un lado pone vastos recursos a disposición de nuestros especialistas, del otro lado impone su propio ritmo y su propia agenda. Los requerimientos del escalafón suelen fomentar una productividad más atenta a la cantidad que a la calidad, o llevan a priorizar los campos de investigación más cotizados del momento. Es evidente que toda institución tiende a imponer su lógica, pero también es posible transitar vías que permitan una intervención más activa en el debate intelectual latinoamericano, y optimizar a su favor los recursos de que se dispone. Lamentablemente los canales de diálogo intra-latinoamericano son más bien débiles. Si los estudios literarios latinoamericanos no han de ser un saber bizantino, sino un discurso con posibilidades de significación social, tienen un importante rol que cumplir en el fortalecimiento de tales canales, apostando así por una América Latina que sigue siendo, en palabras de Ángel Rama, "un proyecto intelectual vanguardista que espera su realización concreta". 